\title{
Research on Financial Ecological Environmental Assessment Index System of Technical Innovation Investment and Financing
}

\author{
Juan Zhao \\ Shandong Yingcai University, Ji'nan, 250001, Chin
}

\begin{abstract}
Keywords: technical innovation, investment and financing, financial ecological environment, assessment index system
\end{abstract}

\begin{abstract}
We should take investment and financing subjects of technical innovation (i.e. the government, financial institutions and technologically innovative enterprises) as the starting point, take technologically innovative enterprises as the center of the investment and financing financial ecological environmental assessment index system, take the government and financial institutions as participants of the internal environment, positively consider external conditions for investment and financing of technical innovation, and propose relevant financial ecological environmental assessment index systems. This paper analyzes the concept and composition of technical innovation investment and financing financial ecological environment, discusses main contents of the technical innovation investment and financing financial ecological environmental assessment index system, and proposes relevant countermeasures to complete China's technical innovation investment and financing financial ecological environmental assessment index system.
\end{abstract}

\section{Introduction}

In recent years, technologically innovative enterprises in China have successfully utilized continuously independent innovation to industrialize considerable scientific and technological achievements, thus improving core competitiveness of China in the field of science and technology. At present, such enterprises have already developed into important hard cores to promote China's national economy and technical development. However, financing difficulty always becomes a great bottleneck perplexing the development of technologically innovative enterprises in China. The reason lies in the philosophies of commercial and financial institutions as strict control of risks and profit maximization, resulting in extremely strict listing conditions, deficient supportive polices of the government for financial intermediaries and obstacles in financing of technologically innovative enterprises in China. At present, the academic world reaches a unanimous agreement that the bad technical innovation investment and financing ecological environment is the most important reason for financing difficulty of technologically innovative enterprises in China. Hence, we should establish and perfect good technical innovation investment and financing financial ecological environmental assessment index systems, so as to give strong supports to technical innovation of enterprises.

\section{Concept and Composition of Technical Innovation Investment and Financing Financial Ecological Environment}

\section{(I) Concept}

Financial ecological environment mainly refers to external environment for survival and development of financial industry and institutional arrangement implemented for self-regulation of impacts on external environment. In a broad sense, financial ecological environment mainly includes political, economic, law, cultural environment and other aspects. In a narrow sense, microcosmic financial ecological environment mainly includes legal system, social credit system, intermediary service system, bank-enterprise relationship system and so on. Various factors above associate with and rely on each other, thereby forming the integrity of financial ecological environment. This paper mainly explores for technical innovation investment and financing financial ecological environment from a microcosmic perspective. In a broad sense, financial 
ecological environment mainly refers to external environment involved in investment and financing of technologically innovative enterprises as well as complicated relations between various subjects and elements in such environment.

\section{(II) Composition}

Investment and financing financial ecological environment of technologically innovative enterprises can be divided into three parts: core circle, internal environment circle and external environment circle. The former refers to three subjects of investment and financing ecological environment and it is the subject of investment and financing of technical innovation. As an important element supporting development of the subject, the internal environment circle is composed of five elements necessary for survival and development of technologically innovative enterprises. The external environment circle generally refers to various system involved in investment and financing of technologically innovative enterprises, mainly including financial market, legal system, credit system and intermediary service agency. The subject of core circle can be allocated in a better way only in a sound external environment circle. Various elements in the internal environment circle should be used to settle investment, financing and other issues of technical innovation, ensure stable development of technologically innovative enterprises and finally realize more harmonious development of technical innovation investment and financing environment.

\section{Main Contents of Technical Innovation Investment and Financing Financial Ecological Environmental Assessment Index System}

\section{(I) Financial Ecological Environmental Assessment Indexes of Enterprise Core Layer}

The first one is technical innovation resource environment of an enterprise. Technical innovation resources of a technologically innovative enterprise will directly determine its R\&D capability and market competitiveness, thereby affecting its capability to develop $f$ external financing. Technical innovation resources of an enterprise are mainly composed of its human resources and financial resources. Scientific and technical personnel, especially research and development personnel of an enterprise, are main forces of the enterprise to implement technical innovation activities. A considerable number of research and development staff with pioneering spirits has already become a key factor for vitality of a technologically innovative enterprise. R\&D funds are always extremely important sources of technical innovation funds of an enterprise. Moreover, R\&D funds will to some extent determine scale continuity of enterprise technical innovation activities. Moreover, $\mathrm{R} \& \mathrm{D}$ fund is one of main indicators reflecting technical innovation resource environment of a technologically innovative enterprise. The author adopts the two indexes (i.e. the number of R\&D personnel in an industrial enterprise above designated size and internal $R \& D$ personnel expenditures in an industrial enterprise above designated size) to investigate technical innovation resource environment of an enterprise.

The second one is credit quality environment of an enterprise. High-quality credit environment, especially credit quality environment of an enterprise, will directly determine smooth implementation of its technical innovation investment and financing activities. Low credit quality of an enterprise generally represents as relatively high value of non-performing loan ratio of this enterprise, thereby damaging credit image of the debit and credit enterprise and even seriously destroying the credit market of a commercial bank and thus affecting debit and credit obtained by technologically innovative enterprise and other faithful enterprises from commercial banks.

\section{(II) Internal Financial Ecological Environmental Assessment Indexes of an Enterprise}

The first one is the support degree of policies. Globally, western developed countries enjoy considerable successful cases in supporting technologically innovative enterprises. In the development process, all foreign enterprises receive great policy supports from local government departments. For instance, American government established the management bureau of small and medium-sized enterprises, and French government established the bank for small and medium-sized enterprises to numerous policy supports to technologically innovative enterprises, including tax reduction, eliminating competitive pressure and providing loans on favorable terms. At present, the government of China has provided some tax supportive policies for technologically innovative 
enterprises and positively encouraged such enterprises for independent innovation. In working practices, the author lists the two indexes (i.e. the government's tax reliefs for industrial enterprises above designated size and government funds in scientific \& technological funds of industrial enterprises above designated size) in the assessment index system.

The second one is the level of financial resources. Generally, technical innovation activities of an enterprise are characterized with high risks. Moreover, such activities have a great demand for funds. If there are inadequate technical innovation funds, technical innovation activities of this enterprise will be in the risk of suspension. To practically solve the issue of innovation funds, it is infeasible to only rely on funds raised by the enterprise. Instead, the enterprise should rely on extremely abundant supports from financial resources. In working practices, the author adopts the two indexes (i.e. loans for technical reform of financial institutions and financial loans in scientific \& technological funds of industrial enterprises above designated size) as important indexes to judge the level of financial resources.

The third one is the diversified development condition of financial institutions. Financial institutions are important channels for indirect financing of technologically innovative enterprises, whose diversified development conditions will directly determine the indirect financing difficulty of such enterprises. For a long time, state-owned holding commercial \& financial institutions play great roles in indirect financing activities of enterprises. In terms of loans for technologically innovative enterprises, however, the risk is relatively great, the scale is relatively small and the credit status is relatively low. For security, mobility and profitability of credit funds, state-owned holding commercial \& financial institutions are always reluctant to accept application for loan. Viewed from practices of western countries, to establish diversified financial institutions (including policy banks, city commercial banks and city commercial banks) is a main approach to practically meet indirect investment and financing requirements of technologically innovative enterprises. In working practices, the author mainly adopts the quantity of financial institutions in the banking industry as an important index to assess the diversified development degree of financial institutions.

\section{(III) External Financial Ecological Environmental Assessment Indexes of an Enterprise}

The first one is the economic development level. It can be said that substantial economy is an important basis for survival and development of a technologically innovative enterprise; while the level of economic development mainly acts on the investment and financing financial ecological environment. In the economic prosperity period, technologically innovative enterprises always have good business performances. Besides, the government's fiscal revenues will increase as well and the running status of financial industry will be relatively favorable. On the one hand, technologically innovative enterprises can master more technical innovation resources and maintain relatively favorable enterprise credit quality, thus quite beneficial for further improvement of the core layer environment. On the other hand, the government can further improve tax reliefs and scientific \& technological funds for technical development, letting the financial industry to provide more fund investments and thus beneficial for developing internal investment and financing environment of technologically innovative enterprises. To this end, the more developed the economic development level is, the more complete the investment and financing financial ecological environment of technologically innovative enterprises will be.

The second one is the legal environment. What inputted by technologically innovative enterprises are mainly finance and intelligence and what produced is knowledge. Once intellectual properties created by considerable finance and intelligence invested by investors and enterprises cannot be protected by laws, it is quite easy to be imitated by others after publicity of such intellectual properties or commercialized input of products. As a result, it is difficult for investors and enterprises to obtain high yield equal to high risks of technical innovation. Therefore, once the legal environment is not strengthening and perfecting enough, intellectual properties that should be protected cannot be completely protected by laws, investors' enthusiasm for investment to technical innovation activities will be certainly affected, finally hindering the development of investment and financing financial ecological environment of technologically innovative enterprises. In working practices, the author mainly adopts the protection degree of intellectual property as main judgment 
index.

\section{Countermeasures for Perfecting Technical Innovation Investment and Financing Financial Ecological Environmental Assessment Index System in China}

\section{(I) Perfect Policy and Regulation System of Investment and Financing in Technologically Innovative Enterprises}

China should gradually establish a comprehensive system of policies and regulations with this law as the center and various auxiliary policies as the supplementation based on such regulations and policies as Law of the People's Republic of China on Promotion of Small and Medium-sized Enterprises. This system should cover preferential tax policies, loan operational approaches, and enterprise credit rating methods and so on.

\section{(II) Positively Expand Investment and Financing Approaches}

The first one is to improve existing indirect investment and financing systems. Commercial bank, an indirect financing dominator, should continue to vigorously give play to the financing function of funds. The government should adopt many methods (e.g. policy orientation, providing enough tax preferences and interest rate means) to positively encourage state-owned commercial banks to give credit and loan supports to technologically innovative enterprises. For instance, certain tax preferences should be offered for loans of technologically innovative enterprises. Interest rate means should be used in a more flexible way, and favorable interest rates given by commercial banks to loans for technical innovation should be continuously increased, so as to represent strong supports of financial policies to technologically innovative enterprises. On this basis, small and medium sized commercial \& financial institutions should be vigorously integrated. Viewed from development experiences of western successful technologically innovative enterprises, small and medium-sized financial institutions are always the most important indirect financing approaches of technologically innovative enterprises. Small and medium-sized commercial \& financial institutions are characterized with flexible use of funds, low requirements for loan approval and simple approval procedures. Moreover, such small and medium-sized commercial \& financial institutions are quite familiar with the local regional economic development and have long-term cooperative relations with local enterprises. Thus, such enterprises can fully reduce information asymmetry between the debit side and the credit side. According to development conditions of present small and medium-sized financial institutions in China, existing small and medium-sized financial institutions can be subject to an overall integration to give full play to their advantages in meeting financing demands of technologically innovative enterprises and to provide better financing services to technologically innovative enterprises.

The second one is to establish multi-layered financial market and set up more complete direct investment and financing systems. On the one hand, we should positively develop multi-layered capital markets, establish a multi-layered market system composed of main board market, small and medium-sized enterprises board market, third board market, growth enterprise board market and others, establish green financing channels for technologically innovative enterprises and give full play to positive functions of above markets in investment and financing. On the other hand, we should accelerate the construction of a bill financing market. In terms of services for technologically innovative enterprises, bill products have many remarkable advantages: first of all, bill products usually have relatively short duration, suitable for technologically innovative enterprises with short period of operating cycle. Then, in terms of short-term loans, bill products are comparatively low in costs and rather flexible in use. Therefore, such products are quite welcomed by technologically innovative enterprises. At last, bill products are closely associated with production links of technologically innovative enterprises. Technologically innovative enterprises can rapidly obtain relevant funds through acceptance or discount of bills and put into production and operation.

(III) Complete Establishment of Auxiliary Investment and Financing Assessment System

Firstly, China should establish a unified enterprise credit assessment auxiliary system as soon as possible. In other words, investment and financing social credit of technologically innovative 
enterprises should be subject to more professional assessment. Moreover, we should set up a database for information sharing, so as to realize information sharing between the government and various financial institutions and other investment subjects and thereby solve the issue of asymmetric information between enterprises and investment subjects and practically reduce the occurrence rate of adverse selection. Secondly, we should form an enterprise credit guarantee working mechanism. A principal element for stint loans of financial institutions for technologically innovative enterprises is that technologically innovative enterprises are involved in insufficient loan collaterals and low credit standing and respectability of guarantors. For this purpose, it is recommended to use internationally universal method. In other words, guarantee institutions are made to undertake $70 \%-80 \%$ of full liabilities. The rest liabilities are undertaken by cooperative financial institutions or other investment subjects.

(IV) Forge a High-quality Investment and Financing Intermediary Service System

Intermediary service institutions with relatively strong service capabilities are absolutely necessary during the establishment of financial ecological environmental assessment system. Intermediary organs provide many investment and financing consultation services to the development of technologically innovative enterprises, letting such enterprises to concentrate on research and development thus to improve their technical innovation capabilities.

\section{Acknowledgments}

The title of this subject: I. relevant issues about the implementation of accounting standards for business enterprises and accounting standards for small enterprises; subject No.: 13CKJJ16; II. research on "cloud innovation" platform providing financial supports to small and medium-sized enterprises, subject No.: 13CJRJ09

\section{References:}

[1] Wen Yuechun, Investment and Financing Strategies of Technical Innovation Development [M], Beijing, Chemical Industry Press, 2010;

[2] Research group of Luoyang Central Branch of People’s Bank of China, Research on Regional Financial Ecological Environmental Assessment Index System [J], Financial Theory \& Practice, 2006 (1);

[3] Han Tingchun and Lei Yingjie, Impacts of Financial Ecological Environment on Development of Financial Main Body [J], World Economy, 2008 (3);

[4] Xu Honglian, Construction of Financial Ecology Quality Evaluation Index System in Rural Areas [J], The Theory and Practice of Finance and Economics, 2008 (7). 